\title{
Scientific Evidence and the Internalism-Externalism Distinction
}

\author{
Jonathan Egeland ${ }^{1}[$ (1)
}

Received: 9 June 2021 / Accepted: 9 August 2021 / Published online: 24 August 2021

(C) The Author(s) 2021

\begin{abstract}
Considerations of scientific evidence are often thought to provide externalism with the dialectical upper hand in the internalism-externalism debate. How so? A couple of reasons are forthcoming in the literature. (1) Williamson (2000) argues that the $\mathrm{E}=\mathrm{K}$ thesis (in contrast to internalism) provides the best explanation for the fact that scientists appear to argue from premises about true propositions (or facts) that are common knowledge among the members of the scientific community. (2) Kelly (Philosophy Compass, 3 (5), 933-955, 2008; 2016) argues that only externalism is suited to account for the public character of scientific evidence. In this article, I respond to Williamson and Kelly's arguments. First, I show that the $\mathrm{E}=\mathrm{K}$ thesis isn't supported by the way in which we talk about scientific evidence, and that it is unable to account for facts about what has been regarded as scientific evidence and as justified scientific belief in the history of science. Second, I argue that there are internalist views that can account for the publicity of scientific evidence, and that those views indeed do better in that regard than the (externalist) view proposed by Kelly. The upshot is that considerations of scientific evidence do not favor externalism over internalism.
\end{abstract}

Keyword Scientific evidence; Evidence; Epistemic internalism; Epistemic externalism; Justification; Publicity

\section{Epistemic Internalism and Externalism}

Given the plausible assumption that facts about justification are not brute facts, but rather that they depend upon one's evidence, epistemic internalism claims that one's evidence is provided by one's internal states. A common way of unpacking the notion of internal states is by saying that one's internal states are one's non-factive mental states, where a mental state is non-factive just in case it doesn't necessarily

Jonathan Egeland

Jonathaneh92@hotmail.com

1 University of Stavanger, Kjell Arholms Hus, 4021 Stavanger, Norway 
have true propositional content. ${ }^{1}$ Epistemic externalism, on the other hand, is naturally then defined as the claim that it isn't the case that all evidence is provided by one's non-factive mental states.

Ever since Edmund Gettier (1963) first exposed the inadequacies inherent in our traditional analysis of our most cherished epistemological concept-namely, knowledge-epistemologists have discussed and debated the internalism-externalism distinction-first by focusing on reliabilism, and later by focusing on the nature and epistemic function of evidence. ${ }^{2}$ Internalists usually argue their case by reflecting on various scenarios in which the subject's rational standing appears to be a function of his or her own first-person perspective on the world. Externalists, on the other hand, often argue their case by reflecting on our concepts of evidence and reason, including the way in which we talk about what our justifying evidence or reasons for belief in various contexts are. ${ }^{3}$ In this article, I will examine two such externalist arguments, both of which have as their conclusion the claim that internalism ultimately must be false insofar as it is unable to account for the way in which the concept of evidence is used in scientific discourse. The first of these arguments is offered by Timothy Williamson (2000) in support of his $\mathrm{E}=\mathrm{K}$ thesis, whereas the second is offered by Thomas Kelly $(2008,2016)$ and focuses on the public or intersubjective character of scientific evidence. In response, I will argue that Williamson's view isn't supported by how we talk about scientific evidence, and that it is unable to account for facts about what has been regarded as scientific evidence and as justified scientific belief in the history of science. And in response to the second argument I will argue that internalist views are just as suited to account for the public character of scientific evidence as externalist views; indeed, they do better in that regard than the externalist view proposed by Kelly.

The article is structured as follows. Section 2 begins from the assumption that facts about justification depend upon one's evidence, while clarifying some confusion about the concept of evidence. Section 3 presents Williamson's views on evidence and the argument for the $\mathrm{E}=\mathrm{K}$ thesis. Section 4 responds to that argument. Section 5 presents the argument that scientific evidence has a public character which internalism cannot account for. Section 6 responds by explaining the way in which

\footnotetext{
1 This position is known as mentalism, and its proponents include Pollock and Cruz (1999); Conee and Feldman (1985); Wedgwood (2002); Smithies (2012); McCain (2016); and Egeland (2019).

${ }^{2}$ Indeed, after the publication of Gettier's seminal article, several epistemologists have shifted their focus from knowledge to justification or evidence. As one commentator puts it: "knowledge is not really the proper central concern of epistemologico-sceptical inquiry. There is not necessarily any lasting discomfort in the claim that, contrary to our preconceptions, we have no genuine knowledge in some broad area of thought-say in the area of theoretical science. We can live with the concession that we do not, strictly, know some of the things we believed ourselves to know, provided we can retain the thought that we are fully justified in accepting them." (Wright, 1991, 88.).

Similarly, focusing primarily on science rather than philosophy, John Earman $(1993,37)$ says that "the main concern is rarely whether or not a scientist 'knows' that some theory is true but rather whether or not she is justified in believing it.".

For a similar take on recent developments in contemporary epistemology, see Williamson $(2000,184)$.

${ }^{3}$ For an excellent introduction to many of the arguments that have made their mark on the internalismexternalism debate (although it fails to cover the kind of externalist argument which this article focuses on), see Littlejohn (2012, introduction).
} 
internalism can account for the publicity of scientific evidence. Section 7 concludes and discusses the role of scientific evidence in the internalism-externalism debate.

\section{Evidence}

Nowadays it is common for epistemologists to think that one's evidence plays a big role in determining what one has justification to believe. In this article, I will follow suit and assume that one's evidence largely is responsible for the propositional justification one has. However, we need to say a little bit more about what evidence is. For all that the assumption above tells us, evidence is whatever justifies belief (or other doxastic attitudes). Consider for example the conception of evidence suggested by Jaegwon Kim:

[T]he concept of evidence is inseparable from that of justification. When we talk of "evidence" in an epistemological sense we are talking about justification: one thing is "evidence" for another just in case the first tends to enhance the reasonableness or justification of the second. . . A strictly nonnormative concept of evidence is not our concept of evidence; it is something that we do not understand. (Kim, 1988, 390-391.) ${ }^{4}$

However, this conception of evidence is too liberal to be theoretically satisfying. Indeed, as Jack Lyons (2016, 1057) also has pointed out, Kim's conception of evidence faces a couple of serious problems. First, it renders evidentialism a wholly uninteresting thesis insofar as it becomes analytically true. If evidence simply is whatever justifies or rationalizes certain doxastic attitudes, then facts about justification will of course be determined by one's evidence. But we already knew that! Our beliefs are justified by whatever justifies our beliefs. There's nothing new under the sun.

Second, Kim's conception of evidence is counterintuitive insofar as it encourages us to conceptualize certain phenomena as evidence that clearly don't appear to be evidence. Consider for example some externalist views of justification, like reliabilism and proper functionalism. ${ }^{5}$ According to such views, the reliability of one's doxastic dispositions or the proper functioning of one's cognitive faculties does (epistemically) contribute to the justification of our beliefs. Hence, according to Kim's conception, such phenomena constitute evidence (on those views). However, this clearly does not seem right. Reliable doxastic dispositions and properly functioning cognitive faculties should not count as evidence-regardless of whether or not theories that emphasize the justifying role played by such phenomena are correct.

How should we conceptualize one's evidence then? I want to suggest as an intuitive conception of evidence, with minimal theoretical commitments, that one's

\footnotetext{
${ }^{4}$ Cf. Kelly (2008, 941-942; 2016).

5 It should of course be noted that not all proponents of reliabilism or proper functionalism take themselves to be offering an analysis of justification.
} 
justifying evidence is the epistemic (as opposed to pragmatic) reasons for belief (or other doxastic attitudes) in one's possession., ${ }^{67}$ This, in other words, means that evidence is the kind of thing that speaks in favor of the truth of certain propositions and which subjects typically find it natural to rely on in the practice of justifying their beliefs-i.e., in demonstrating what their beliefs have going for them that serve as indicators of their being true. Moreover, it also means that justifying evidencei.e., the kind of evidence that justifies belief-must somehow belong to a subject. In order for someone to have a piece of evidence, it cannot simply be the case that the evidence exists somewhere in the world. Instead, the evidence must somehow be in the subject's cognitive possession; otherwise, it wouldn't be evidence that one has or is in possession of. ${ }^{8}$

Continuing, I will rely on this intuitive conception of evidence in my discussion of the two externalist arguments purporting to show that there is a specific species of evidence — namely, scientific evidence - that only can be accommodated in an externalist framework. Let's begin by turning to Williamson's views on the matter and the argument for the $\mathrm{E}=\mathrm{K}$ thesis.

\section{Williamson on Scientific Evidence and the $E=K$ Thesis}

Williamson thinks that only true propositions (or facts) can be evidence. First, he thinks that all evidence is propositional since one's evidence can be evaluated for properties like consistency and inconsistency, coherence, probabilification, entailment, explanatory fit, and the like. Such properties only hold among items that can be considered true or false, which means that they must be propositions. Indeed, he thinks that "propositionality is essential to the functional role of evidence" (Williamson, 2007b, 209, footnote 1). ${ }^{9}$ Second, Williamson thinks that only a proper subset of all propositions can be evidence-namely, the true ones-since propositions that are inconsistent with one's evidence must be false. If propositions inconsistent with one's evidence must be false, then it follows that the propositions that constitute one's evidence must be true. ${ }^{10}$ Thus, Williamson thinks that all evidence

\footnotetext{
6 Although I do not have space to discuss his article, I think this suggestion avoids Brunero's (2018) counterexamples to the reasons-as-evidence view.

7 For a similar suggestion, see Brogaard (2018).

8 The present suggestion is neutral on the question of whether one's evidence/reasons are propositionally specified. For more comprehensive (and disagreeing) treatments of this issue, see Turri (2009) and Glüer and Wikforss (2018).

9 Williamson (2000, 194-196) appears to offer three different, but similar, arguments for the claim that all evidence is propositional. The first (194-195) argues from the fact that evidence typically is used in abductive reasoning; the second (195-196) argues from the role of evidence in probabilistic reasoning; and the third (196) argues from the fact that evidence sometimes can be used to rule out hypotheses.

10 Williamson $(2007 \mathrm{~b}, 209)$ puts the point as follows: "Why is it bad for an assertion to be inconsistent with the evidence? A natural answer is: because then it is false. That answer assumes that evidence consists only of true propositions. For if an untrue proposition $p$ is evidence, the proposition that $p$ is untrue is true but inconsistent with the evidence. Using 'fact' for 'true proposition,' we may say that evidence consists only of facts." However, this is clearly a question-begging response to those who don't assume that evidence must be true.
} 
consists of true propositions that support certain (other) propositions by deductively entailing them, by increasing their probability, or by abductively supporting them.

Moreover, Williamson also agrees that in order for evidence to play a justifying role it must somehow be in the subject's cognitive possession. More specifically, he thinks that the subject somehow must grasp the propositions that are included in his evidence:

One can use an hypothesis to explain why A only if one grasps the proposition that A. Thus only propositions which one grasps can function as evidence in one's inferences to the best explanation. By this standard, only propositions which one grasps count as part of one's evidence. (Williamson, 2000, 195.)

However, he doesn't think that it is sufficient for a subject to believe a true proposition $p$ in order for $p$ to be included in his evidence. Rather, what is required is that the subject knows $p$. Thus, only knowledge is evidence. ${ }^{11}$ Moreover, he also thinks that all knowledge is evidence, which leads him to endorse the famous $\mathrm{E}=\mathrm{K}$ thesis:

$E=K$ : "knowledge, and only knowledge, constitutes evidence" (Williamson, 2000, 185).

And later he endorses what we may call the $R=K$ thesis:

$R=K^{\prime \prime} p$ is available to you as a reason if and only if you know $p$." (Williamson, 2007a, 120.)

The $\mathrm{E}=\mathrm{K}$ thesis is clearly an externalist theory of justification and evidence (and the same also goes for the $\mathrm{R}=\mathrm{K}$ thesis, of course). This can easily be seen by comparing knowledge with internal states. Under the definition of internalism that we're currently considering, internal states are non-factive mental states. By contrast, knowledge is a factive state since it necessarily has true propositional content. ${ }^{12}$ It therefore fails to qualify as an internal state, and if knowledge cannot be considered an internal state, while at the same time providing evidence for our beliefs, then $\mathrm{E}=\mathrm{K}$ must be an externalist theory.

Williamson offers several considerations in favor of the $\mathrm{E}=\mathrm{K}$ thesis. ${ }^{13}$ Here I want to take a closer look at one of the less discussed reasons he offers. ${ }^{14}$ As he sees it, in the scientific discourse, a body of evidence is treated as consisting of true propositions that are commonly known (or perhaps just widely available) in the scientific community. This is how he puts it in his Knowledge and Its Limits:

\footnotetext{
11 To support this claim, Williamson (2000, 200-201) offers the now well-known "balls in a bag" argument. For a critical discussion of the argument, see Lyons (2016, 1060-1061).

${ }^{12}$ I say that knowledge is a factive state, rather than a factive mental state, because I don't want to commit myself to the view that it actually is a mental state. Williamson (2000) of course claims that it is, but there are strong arguments for the opposite view; see, e.g., McGlynn (2014, Ch. 8).

${ }^{13}$ See Williamson (2000, Ch. 9).

${ }^{14}$ The argument is really an objection to the internalist's conception of evidence, although it can be formulated without omitting any of his central points, as I do here, as an argument for the $\mathrm{E}=\mathrm{K}$ thesis. Indeed, since the passage quoted from Williamson (2000) occurs in the middle of his chapter on evidence, where he argues that the $\mathrm{E}=\mathrm{K}$ thesis is superior to more traditional internalist conceptions of evidence, I think an argument along the lines I present is hinted at in that chapter.
} 
If one's evidence were restricted to the contents of one's own mind, it could not play the role it actually does in science. The evidence for the proposition that the sun is larger than the earth is not just my present experiences or degrees of belief. If the evidence is widened to include other people's experiences or degrees of belief, or my past ones, then my identification of it becomes even more fallible. In any case, that does not seem to be the right widening; it is more plausible that the evidence for a scientific theory is the sort of thing which is made public in scientific journals. (Williamson, 2000, 193.)

And later in The Philosophy of Philosophy, he writes:

It is fanciful to regard evidence in the natural sciences as consisting of psychological facts rather than, for example, facts about the results of experiments and measurements. When scientists state their evidence in their publications, they state mainly non-psychological facts (unless they are psychologists); are they not best placed to know what their evidence is? (Williamson, 2007b, 212.)

In these passages, Williamson claims that when scientists argue for theories or hypotheses-like that the sun is larger than the earth-they don't rely on premises about their internal states as evidence for them. Rather, they argue from premises about true propositions (or facts) that are common knowledge among the members of the scientific community, ${ }^{15}$ which is easily explained by his $\mathrm{E}=\mathrm{K}$ thesis. Indeed, according to the $\mathrm{E}=\mathrm{K}$ thesis, the reason we find it so natural to treat our knowledge as evidence in the scientific discourse (and other kinds discourse as well) is because it $i s$ our evidence.

Moreover, this is also thought to pose a big problem for the internalist. Indeed, Williamson's point can be presented as a modus tollens against internalism. To see why that is so, recall that internalism holds that facts about which doxastic attitudes one now has justification (to a certain degree) to hold supervene upon one's non-factive mental states. Thus defined, it follows from internalism that a pair of epistemic agents, one of whom is in a normal scenario where everything is as it seems and the other of whom is in a subjectively indistinguishable deceptive scenario (like those that typically involve envatment or Cartesian demons), have the same evidence and are equally justified in holding the same beliefs. However, if Williamson's point is correct, then agents in subjectively indistinguishable normal and deceptive scenarios need not have the same (scientific) evidence (since one of them can have knowledge that the other lacks) and can therefore fail to be equally justified in holding the same beliefs-in which case internalism must be false. ${ }^{16}$

\footnotetext{
15 The notion of common knowledge that I believe Williamson here (implicitly) is operating with is an intuitive notion; it is not the notion that we find in epistemic logics. According to the latter notion, $\Phi$ is common knowledge among the agents in $\mathbf{A}$ if and only if (i) $\Phi$ is true, (ii) everybody in $\mathbf{A}$ knows that $\Phi$ is true, (iii) everybody in $\mathbf{A}$ knows that everybody in $\mathbf{A}$ knows that $\Phi$ is true, and (iv) everybody in $\mathbf{A}$ knows that,..., everybody in $\mathbf{A}$ knows that $\Phi$ is true, ad infinitum: $C_{\mathbf{A}} \Phi=\Phi \wedge \mathrm{K}_{\mathbf{A}} \Phi \wedge \mathrm{K}_{\mathbf{A}} \mathrm{K}_{\mathbf{A}} \Phi \wedge$ $\mathrm{K}_{\mathrm{A}} \mathrm{K}_{\mathrm{A}} \mathrm{K}_{\mathrm{A}} \Phi \ldots$

16 "That one has the same evidence in the good and bad cases is a severe constraint on the nature of evidence. It is inconsistent with the view that evidence consist of true propositions like those standardly offered as evidence for scientific theories." (Williamson, 2000, 173.).
} 


\section{Response to Williamson on Scientific Evidence}

In response to the argument that our conception of scientific evidence strongly supports the $\mathrm{E}=\mathrm{K}$ thesis, and hence externalism in general, I will make three points as to why that isn't the case.

First, talk about evidence, both in scientific and everyday contexts, doesn't support the $\mathrm{E}=\mathrm{K}$ thesis. Instead, it supports only a more moderate version of externalism according to which both internal states and external factors count as evidence. ${ }^{17}$ To see why that is so, notice that we often talk about evidence without referring to our knowledge. For example, if someone asks you what your evidence for believing that the Berlin wall fell on June 13th, 1990, is, it is completely natural to answer by pointing to an encyclopedia article in front of you, saying that "my evidence is right there, just take look yourself" - which refers to a physical object (i.e., the encyclopedia article), rather than a proposition you know, as your evidence. Or you can answer simply by saying that "I experienced the event myself"-which refers to an internal state as evidence. ${ }^{18}$ Either way, our ordinary and everyday talk about evidence doesn't support the $\mathrm{E}=\mathrm{K}$ thesis.

Similarly, when we talk about scientific evidence, we also often talk as if internal states and external factors besides propositions we know are evidence. For example, if someone asks you what your evidence for a certain hypothesis $h$ is, a natural reply is that "my evidence for $h$ was gathered during last year's excavation"-which again refers to physical objects (i.e., those that were gathered at the excavation), rather than known propositions, as scientific evidence. Or, another natural way of answering the question is to say that "the evidence for the hypothesis $h$ is observations $o_{1}, \ldots, o_{n}$ "-which refers to internal states as scientific evidence. So even though we sometimes do refer to our knowledge as (scientific) evidence (either explicitly or implicitly), talk about evidence, both in scientific and everyday contexts, only seems to support a somewhat moderate externalism, according to which both internal states and external factors can provide (scientific) evidence. ${ }^{19}$

Second, the $\mathrm{E}=\mathrm{K}$ thesis isn't supported by our intuitive conception of scientific evidence since it is possible that there are false propositions included in our

\footnotetext{
${ }^{17}$ A similar point is also made by Turri (2009) and Kelly (2008).

${ }^{18}$ An anonymous reviewer helpfully suggested that this need not count against $\mathrm{E}=\mathrm{K}$, since you know that you had the relevant experience. However, in response, I claim that it is possible that you (in the hypothetical) only think that you had the experience, but without actually knowing that to be the case. Indeed, you may have a justified true belief that you had the experience, but without knowing so, since you don't satisfy whatever "no-Gettier" condition is required to turn a justified true belief into knowledge. Moreover, even though the experience is not included in the content of some relevant higher-order knowledge, it still functions as evidence-in which case it does count against the $\mathrm{E}=\mathrm{K}$ thesis. I want to thank the reviewer for pressing me on this point.

${ }^{19}$ In fact, to the extent that the notion of "public evidence" can be analyzed in internalist terms (which I argue that it can in Sect. 6), it doesn't even support that much. If there indeed is such an analysis available, then this fact about language use supports internalism.

Moreover, it should also be noted that this "moderate externalism" actually is compatible with internalism insofar its proponents can argue that although both internal and external factors can count as (scientific) evidence, only internal factors can count as justifying evidence.
} 
scientific evidence. For example, we can imagine scientific propositions that are false but rightly treated as evidence since they enjoy great predictive success and are strongly corroborated by other things we know. Indeed, not only can we imagine such scenarios, but we also seem to find them in the actual history of science. ${ }^{20}$

Consider the curious case of Bohr and Sommerfield who, by relying on a flawed model of the atom in which electrons literally orbit the nucleus in a circular or elliptical fashion, successfully predicted the spectral lines of various elements. ${ }^{21}$ At the end of the nineteenth century and the beginning of the twentieth century, a problematic and up to that point unexplained phenomenon was the characteristic spectra of different elements; every element emits and absorbs light only at certain specific frequencies. Before Bohr, most explanations of the phenomenon were no more than farfetched speculations. ${ }^{22}$ However, in 1913, Bohr explained the spectral lines of any element in terms of the possible orbits of the electrons in the element's atoms. His theory had tremendous success in explaining the spectral lines of ionized helium. The physicist and science historian Abraham Pais writes as follows about the event:

Up to that time no one had ever produced anything like it in the realm of spectroscopy, agreement between theory and experiment up to five significant figures. (Pais, 1991, 149.)

Indeed, his theory was so successful that many of his contemporaries were absolutely convinced that it had to be correct. Einstein, for example, said that "this is a tremendous result. The theory of Bohr must then be right."23

Nevertheless, as it turns out, Bohr's theory wasn't able to explain the spectral lines of hydrogen. So in 1916 Sommerfield further developed Bohr's initial theory and was able to offer accurate predictions. The expanded theory of Sommerfield was indeed so successful that by 1920 there was almost universal agreement among the physicists of the time that the theory not only had to be correct, but that it was the only viable model for atomic and quantum research. ${ }^{24}$ In fact, the formula Sommerfield derived from his theory in order to explain the frequency at which hydrogen emits and absorbs light is the exact same as the one that we nowadays use for the same purpose. However, as it turns out, we now know that the Bohr-Sommerfield theory is wrong, and it has been replaced with a new theoretical model (which includes the Schrödinger equation). Yet, it remains a fantastic coincidence that Sommerfield was able to derive the correct formula from a wholly inadequate theory. ${ }^{25}$

\footnotetext{
20 There are also many counterexamples to the claim that false propositions cannot be included in one's evidence in everyday situations. See, e.g., Warfield (2005); Klein (2008); Fitelson (2010); Arnold (2011); Rizzeri (2011); and Egeland (forthcoming). Littlejohn (2012, 106-109), however, critically argues against some these examples, and McCain (2016, 25-27) responds to his argument.

${ }^{21}$ For an interesting discussion of the case, which relates it to the realism/anti-realism debate, see Vickers (2012).

22 According to Pais (1986, 197): "So it was when Bohr came along. In his words, in those early days spectra were as interesting and incomprehensible as the colors of a butterfly's wing.".

23 Cited in Pais (1991, 154).

24 See Kragh (2012, Ch. 4).

25 Kronig (cited in Kragh, 1985, 84), for example, says that it is "perhaps the most remarkable numerical coincidence in the history of physics.".
} 
In his discussion of the development, acceptance, and eventual rejection of the BohrSommerfield theory, Helge Kragh offers the following remark:

By some sort of historical magic, Sommerfield managed in 1916 to get the correct formula from what turned out to be an utterly inadequate model. . . [This] illustrates the well-known fact that incorrect physical theories may well lead to correct formulae and predictions. (Kragh, 1985, 84.)

Now, for the present purposes, the question we need to ask is whether the false Bohr-Sommerfield theory (or the false propositions comprising it) did, or at least could, count as evidence for other scientific hypotheses once it became clear that it was able to successfully explain the observational data about spectral lines? I think we should answer in the affirmative. The false Bohr-Sommerfield theory clearly played an important theoretical role in the epistemologico-scientific project at the time; indeed, so much so that when Sommerfield derived the true formula that successfully explained the relevant data from his theory, the theory itself became justified to such a degree that it could be used as scientific evidence for other hypotheses or derivations., ${ }^{2627}$ If, for example, the theory could be shown to support a certain interesting and not yet empirically tested hypothesis, then it does seem that we would have good reason to believe in that hypothesis. More specifically, Sommerfield's theory, which itself was justified by its explanatory power and predictive success, would provide evidence in favor of said hypothesis by conferring (some of) its justification upon it. Moreover, not only does this seem intuitive, it appears to be more or less what actually happened. Before its eventual downfall, when the BohrSommerfield theory enjoyed almost universal support among contemporary physicists, the theory, with all its success, was, as noted above, thought to provide the only viable model for further research in the field. Indeed, not only does the theory appear to have been accorded evidential significance, it also appears to have created something like a scientific paradigm, ${ }^{28}$ the basis of which could be used in order to epistemically evaluate and justify further research — at least for a time.

A possible-perhaps even obvious-objection to my argument is that the BohrSommerfield theory eventually was overturned and recognized as false, and that it therefore didn't really provide bona fide scientific evidence to begin with. Although it is completely understandable why physicists in the early twentieth century might have believed that the theory was true and should be included in their evidence set,

\footnotetext{
26 If someone were to object that we shouldn't think of scientific theories or propositions as scientific evidence, which is more akin to observational data, then I would be happy to concede that such theories/ propositions are evidentially significant, but aren't scientific evidence. And that, moreover, is sufficient to counter the $\mathrm{E}=\mathrm{K}$ thesis. All that is required is that false theories/propositions can function as evidence, scientific or other.

27 Indeed, this is precisely why the Bohr-Sommerfield case is an example of "historical magic"-to use a term from Kragh. It is not because the derivation in question was made on the basis of something nonevidential, but because it was made on the basis of something non-true.

28 Although not necessarily in the sense that Kuhn (1996) uses the term.
} 
the fact that it is false shows their belief to have been mistaken. In response, I want to point out the extreme skeptical consequences that seem to follow from this line of thought. For if one bites the bullet and says, contrary to intuition, that false (but strongly corroborated) scientific propositions cannot function as evidence, then beliefs based on those propositions cannot be justified (at least not by the propositions themselves). And if this truly is the case, then the history of science doesn't only appear to be filled with scientifically informed and ever more sophisticated false beliefs that (hopefully at least) gradually approximate the truth, but it is also filled with scientifically informed ever more sophisticated unjustified beliefs. But I don't think that this is the sort of skepticism we want to live with. If it were true, then the history of science would present us with a wonderful and gradually changing picture of the universe, albeit one that for the most part is unjustified. Moreover, by pessimistic meta-induction, we might not only be compelled to conclude that our present picture of the universe most likely is false (for the most part), but also that it isn't even justified. However, since we clearly do seem to be justified in holding our scientific world-view and our scientifically informed beliefs (at least most of them), I therefore think that the objection ultimately fails.

Another problem with the objection is that something similar to the Bohr-Sommerfield case appears to be going on today, especially when it comes to our reliance on scientific theories or models that strictly speaking are false or inaccurate, and which we may know to be false/inaccurate, but which nevertheless are accorded evidential significance. Good examples are provided by models involving idealizations, smoothing of data sets, ${ }^{29}$ or ceteris paribus clauses. Although such models often will be false or inaccurate, ${ }^{30}$ they can be very useful in calculating or predicting the outcome of experiments or real world events. They are, as Catherine Elgin (2017) recently put it, "felicitous falsehoods"-i.e., falsehoods which are "true enough" insofar as they are essential to our scientific practice, justify our acceptance of various theories and hypotheses, and contribute to our understanding of certain scientific topics and domains. ${ }^{31}$ Elgin provides an illuminating study of many such models. For example, astronomers often rely on models which don't take into account

\footnotetext{
${ }^{29}$ To smooth a data set is to create an approximating function that captures the most important patterns in the data, while leaving out noise or statistically unlikely occurrences.

${ }^{30}$ One might think that this is an odd statement to make, and that scientific models don't have truthvalues since they aren't propositional. However, my view is that scientific models-not unlike normal sentences - can express propositions that of course can be true of false.

31 Following a recent trend in epistemology and philosophy of science (see, e.g., Grimm, Baumberger, \& Ammon (2017)), Elgin claims that the purpose of science (or at least one of its purposes) is to facilitate understanding rather than (propositional) knowledge. Understanding, moreover, involves competent use of the information one has in the furthering of one's epistemic goals: "To understand a topic involves knowing how to wield one's commitments to further one's epistemic ends. It involves being able to draw inferences, raise questions, frame potentially fruitful inquiries, and so forth. Since some of the commitments are likely to be felicitous falsehoods and others to be methodological or normative commitments that are not truth apt, understanding is not factive. It is not a type of knowledge; it does not consist exclusively or primarily in believing or accepting truths." (Elgin, 2017, 3.).
} 
important features of planets, or which simply treat them as point masses without spatial extension when they want to calculate their motion (see Elgin, 2017, 27). Yet, despite systematically misrepresenting their objects of study in important ways, such models are evidentially significant insofar they contribute (epistemically) to the justification of various theories, hypotheses, or beliefs-or so I suggest. Although she is less appreciative of traditional epistemological notions-such as "belief, assertion, and knowledge" 32 _Elgin similarly stresses the epistemic importance that felicitously false models have, claiming that their falsity or inaccuracy "does not undermine [their] epistemic function[s]" (Elgin, 2017, 3).

The third problem with Williamson's view on scientific evidence is that there are many deception scenarios that seem to provide strong support for internalism, and hence against the $\mathrm{E}=\mathrm{K}$ thesis. The kind of argument that $\mathrm{I}$ have in mind has played an important role in the epistemological literature on the internalism-externalism debate, but has had much less influence on discussions about scientific evidence in particular. ${ }^{33}$ Consider, for example, your favorite deception scenario. In it, everything seems to be just as if it isn't a deception scenario, even though it is. Indeed, it is subjectively indistinguishable from the corresponding good or normal scenario. As a result, despite their falsity and unreliability, our scientific theories and beliefs seem to be just as justified as they would have been in the corresponding good scenario. And this strongly supports the claim that our scientific evidence doesn't depend on typical external factors like knowledge, truth, or reliability. Instead, it only depends on factors that the normal and deceptive scenarios have in common-the best candidate of which is our internal states. So reflection on deception scenarios and the epistemic status of our scientific theories and beliefs in those scenarios provides strong intuitive support for internalism. And, moreover, since internalism is incompatible with the $\mathrm{E}=\mathrm{K}$ thesis, it also counts against Williamson's position. $^{34}$

Taken together, these three points show that, on balance, we have a conception of scientific evidence that Williamson's $\mathrm{E}=\mathrm{K}$ thesis cannot account for. Philosophical reflection on scientific evidence shouldn't be seen as providing an argument for epistemic externalism via the $\mathrm{E}=\mathrm{K}$ thesis. However, whether it supports internalism or a more moderate version of externalism remains to be seen. Much of the disagreement between the positions appears to depend on different intuitions (or different beliefs about their epistemic significance) about how we

\footnotetext{
32 Elgin $(2017,9)$.

33 The locus classicus of the argument is provided by Lehrer and Cohen (1983).

34 Williamson (2007a) has responded to this kind of argument by drawing a distinction between justification and blamelessness, while claiming that victims of deceptions scenarios are blamelessly unjustified in holding their beliefs. However, a problem with Williamson's response, first pointed out by Pryor (2001), is that it commits him to having to give highly counterintuitive verdicts about other scenarios. Other, more recent worries are raised by Greco (forthcoming).
} 
should evaluate epistemic agents (and theories/beliefs) in deception scenarios. ${ }^{35}$ Recently, I have defended the view that our philosophical intuitions about such cases provide strong support for internalism against various counterarguments. ${ }^{36}$ However, I will not revisit this issue here. Instead, in the next section, I will discuss a feature of scientific evidence that often is thought to provide a very strong argument—indeed, perhaps even a knockdown argument—against internalism, namely, its public character.

\section{The Public Character of Scientific Evidence}

Scientific evidence is often believed to have a public character insofar as it can be appreciated and shared by different people. For example, according to Carl Hempel:

[A]ll statements of empirical science are capable of test by reference to evidence which is public, i.e., evidence which can be secured by different observers and does not depend essentially on the observer. (Hempel, 1952, 22.)

Similarly, Karl Popper writes:

The objectivity of scientific statements lies in the fact that they can be intersubjectively tested. (Popper, 1959, 44.)

The publicity of scientific evidence has for several decades been thought to create problems for internalism, since the internalist conception of evidence seems to require that it have a much more private character (cf. Kelly, 2016). Peter Railton remarks:

\footnotetext{
35 Another source of disagreement concerns the relevance of the internalism-externalism debate in philosophy of mind for the internalism-externalism debate in epistemology. Whether or not externalism in the philosophy of mind supports externalism in epistemology by (i) entailing epistemic externalism and (ii) receiving intuitive support from reflection on various scenarios is a contested issue. To evaluate this kind of argument, it is important to note that externalism in the philosophy of mind can mean either content externalism, which says that some mental states have contents that are individuated in virtue of relations to the external environment, or vehicle externalism, which says that some mental states (as vehicles of content) are individuated in virtue of relations to the external environment. In the literature, three arguments have been offered for the view that content externalism entails epistemic externalism: BonJour's (1992) Accessibility Argument, Boghossian's (1989) Self-Knowledge Argument, and Chase's (2001) Process Argument. However, all of the arguments rely on contentious premises and therefore remain unconvincing. When it comes to the view that vehicle externalism entails epistemic externalism, fewer arguments have been offered in the literature. However, a couple of recent arguments by Carter et al. (2014) and Smithies (2018) plausibly suggest that accessibilism, together with certain plausible background assumptions, is incompatible with vehicle externalism. A reasonable, albeit somewhat tentative conclusion to draw from these discussions is that although epistemic internalists will have a hard time squaring their position with vehicle externalism, they should be able to endorse externalism about content without inconsistency - at the very least, doing so seems to be "a live option," as Carter et al. (2014) put it in their review of the current literature about these issues.

That being said, it would be somewhat odd to characterize a mentalist who thinks that non-factive mental states with externally individuated content can play a role in conferring justification upon one's doxastic attitudes as an internalist, since this in effect would mean that the one's evidence in some sense includes things that are external to the subject's mind.
}

${ }^{36}$ See Egeland (2019). 
[O]bjective inquiry uses procedures that are intersubjective and independent of particular individuals and circumstances-e.g., its experiments are reproducible, its methods are determinate, its criteria are effective, and it makes no essential use of introspective or subjectively privileged evidence in theory assessment. ${ }^{3738}$ (Railton, 1984, 815.)

As recently has been made much more clear by Kelly, the problem for the internalist is that they cannot easily explain how scientific evidence comes to be shared by multiple individuals in the objective pursuit of scientific knowledge. As Kelly sees it, the internalist conception of evidence-which he occasionally, following Williamson $(2000,173)$, calls the phenomenal conception of evidence ${ }^{39}$ - cannot account for the actual scientific practice wherein evidence is shared among different individuals in order to further the scientific project. This is how he puts it:

[T] he phenomenal conception of evidence would seem to fit poorly with the way in which the concept is employed in scientific and legal contexts. Notably, in such contexts, a large value is placed on the publicity of evidence, i.e., on the fact that paradigmatic evidence is something that can be shared by multiple individuals. Indeed, it is this public character of evidence which is often taken to underwrite the possibility of an inquiry that is genuinely objective. If evidence is taken to include (e.g.) facts about the external world, then, inasmuch as multiple individuals can be aware of the same facts, one and the same piece of evidence can literally be shared by those individuals. In contrast, a view according to which my evidence is limited to my own non-factive mental states does not seem to allow for this, inasmuch as I do not literally share my own token mental states with anyone else. At best, the sense in which evidence can be shared by multiple individuals on such a picture is a matter of their being in distinct but similar mental states (perhaps: token experiential states of the same type). It is far from obvious that such a surrogate would provide the kind of objectivity which literally shared public evidence is often taken to afford. (Kelly, 2008, 949-950.)

37 Cf. Hempel (1952) and Feigl (1953), the latter of whom says: "The quest for scientific knowledge is... regulated by certain standards of criteria... The most important of these regulative ideas are:

1. Intersubjective Testability. This is only a more adequate formulation of what is generally meant by the 'objectivity' of science. What is here involved is... the requirement that the knowledge claims of science be in principle capable of test... on the part of any person properly equipped with intelligence and the technical devices of observation or experimentation. The term intersubjective stresses the social nature of the scientific enterprise. If there be any 'truths' that are accessible only to privileged individuals, such as mystics or visionaries - that is, knowledge-claims which by their very nature cannot independently be checked by anyone else - then such 'truths' are not of the kind that we seek in the sciences. The criterion of intersubjective testability thus delimits the scientific from the nonscientific activities of man." (Feigl, 1953, 11.).

38 Railton's statement is very strong. As a result, it fails to account for the fact that introspective reports by subjects provide key data in contemporary cognitive science and psychophysics-especially in the study of consciousness. For a more detailed discussion of this issue, see Goldman (1997).

39 This is actually a misnomer since even though some internalists do have a phenomenal conception of evidence, not all do. 
Here, Kelly not only tells us that internalism will have a difficult time accounting for the public character of scientific evidence, he also provides an (externalist) example of what such evidence may consist of that does account for its publicity. He says that our scientific evidence may (at least for the most part) be comprised of facts about the external world. Moreover, as will become clear (in the quoted paragraphs below), facts about the external world should most naturally be understood as physical objects or states of affairs in which such objects figure, rather than true propositions. On this picture, it is mind-independent objects and the relations among them-like, for example, rock formations, cells in a petri dish, or bone fragments found at burial sites - that constitute the evidence for our scientific theories and hypotheses, and which make relevant propositions about those objects and states of affairs true. $^{40}$

This kind of evidence has aptly been called "scientific evidence" (Conee \& Feldman, 2008) and "factual evidence" (Lyons, 2016) in the literature, and Kelly's view appears to receive support from the way in which we often find ourselves talking about scientific evidence. For example, we often talk about gathering evidencewhether it be fingerprints, rocks, or any other such object-which seems to assume that physical objects can function as evidence. Moreover, it isn't hard to see why Kelly, with his claim that scientific evidence is comprised of facts (understood in the manner above), easily will be able to explain the public character of scientific evidence. Since such facts typically are accessible to different observers or experimenters - the bone fragments found at ancient burial sites are in principle available for study by different scientists - the evidence they provide can literally be shared by different people. These are exactly the points Kelly (2016) makes in his Stanford Encyclopedia article on evidence:

This [internalist] picture of evidence stands in no small measure of tension with the idea that a central function of evidence is to serve as a neutral arbiter among competing views. For it is natural to think that the ability of evidence to play this latter role depends crucially on its having an essentially public character, i.e., that it is the sort of thing which can be grasped and appreciated by multiple individuals. Here, the most natural contenders would seem to be physical objects and the states of affairs and events in which they participate, since it is such entities that are characteristically accessible to multiple observers. (I ask what evidence there is for your diagnosis that the patient suffers from measles; in response, you might simply point to or demonstrate the lesions on her skin.)

Here, Kelly points out that the internalist will have a hard time accounting for the public character of scientific evidence, before arguing that the view which most naturally explains the publicity of evidence is one according to which one's evidence consists of physical objects and the states of affairs and events in which they figure. Moreover, he continues to press the point that internalism, in contrast to his

\footnotetext{
40 Thus, the view clearly differs from that of Williamson, who thinks that it is the propositions we know that constitute our evidence.
} 
own view, is incompatible with the public character of scientific evidence and that it therefore cannot account for scientific objectivity:

On the other hand, to the extent that one's evidence consists of essentially private states there would seem to be no possibility of sharing one's evidence with others. But it is precisely the possibility of sharing relevant evidence which is naturally thought to secure the objectivity of science. Indeed, it has often been held that inasmuch as the objectivity of science is underwritten by the fact that science is evidence driven, it is the public character of scientific evidence which is crucial. On this view, it is a central methodological norm of science to eschew as inadmissible (e.g.) any alleged episodes of incommunicable insight in considering whether to accept or reject a claim.

According to Kelly, internalism is therefore unable, or at the very least hard pressed, to account for the public character of scientific evidence. As he sees it, a much more plausible (externalist) view holds that our scientific evidence consists of facts about the external world, understood in terms of mind-independent physical objects and the states of affairs in which they figure. Contrary to internalism, such a view is clearly able to account for the publicity of scientific evidence insofar as facts (in principle) can be gathered, observed, shared, and studied by multiple individuals.

\section{Response to Kelly on the Publicity of Scientific Evidence}

Before I explain why I think that the internalist can account for the publicity of scientific evidence, I'm going argue that Kelly's view on the matter is problematic insofar as the picture of scientific evidence that it presents isn't epistemologically interesting. I take it that any epistemologically interesting theory of evidence must present it as something that makes an epistemic difference by rationalizing or justifying belief in certain inferentially supported propositions. However, this is precisely what Kelly's view fails to do. The problem, more specifically, is that if facts, understood as physical objects and the relations between them, are scientific evidence, then it is possible to have scientific evidence that doesn't make an epistemic difference since the evidence (contrary to what was established in Sect. 2) needn't be in our cognitive possession. For example, there may some object—e.g., cells in a petri dish, bone fragments, and pieces of old parchment —on a table next to me, but that is not in itself sufficient to justify me (or anyone else) in believing any proposition. There may thus be a sense in which the object counts as "evidence" (or something approximating evidence) — after all, a colleague may tell you to "look at the evidence gathered on the table next to you"-but it isn't evidence in any epistemologically interesting sense. A similar point is also made by Earl Conee and Richard Feldman, who write as follows about the view that facts are evidence:

Suppose that some factor, $\mathrm{S}$, is scientific evidence, for some condition, C. . . [O] ne can [then] have scientific evidence without having any reason at all to believe what that scientific evidence supports. . More generally, something can be 
scientific evidence for a proposition without being justifying evidence for that proposition. Justifying evidence is by itself a reason for belief, something one could in principle cite as a justifying basis for belief. (Conee \& Feldman, 2008, $84-85.)^{41}$

So if we allow facts (in Kelly's sense) to function as scientific evidence, then it becomes possible to have evidence that doesn't have any rational or justificatory force. $^{42}$

This, however, is a problem that neither the internalist nor the externalist need be burdened with. Both kinds of view can account for the fact that we somehow need to be in cognitive possession of our evidence. Consider, for example, Williamson's $\mathrm{E}=\mathrm{K}$ thesis again. According to it, only a proper subset of the true propositions is evidence. What is required in order for a true proposition to function as evidence is that it is grasped in the right sort of way, or, in other words, that it is known. And knowing a proposition to be true is clearly sufficient in order to possess that proposition as justifying evidence. Similarly, the internalist can also satisfy the possession requirement by, for example, claiming that only propositions that are the contents of some of our attitudes (e.g., our beliefs or experiences) can function as justifying evidence. The propositions, according to the internalist, will not necessarily all be true, but, as we saw above, this shouldn't stop them from having justificatory force. Our evidence, scientific and other, can include false propositions.

Now having argued that Kelly's view fails to be epistemologically interesting insofar as it counts as scientific evidence factors that need not make an epistemic difference when it comes to which propositions we have justification to believe, ${ }^{43}$ and that this is a problem which neither internalists nor externalists must face, I will now explain why standard internalist and externalist views can account for the public character of scientific evidence. If it thus turns out that Kelly's view faces problems that other internalist and externalist views don't face, while the latter views also can account for the publicity of scientific evidence, then we will have good reason to reject Kelly's view in favor of the less problematic internalist/externalist views. Let me begin by pointing out two different ways in which scientific evidence appears to be public. On the one hand, scientific evidence appears to be the kind of thing that typically is shared between multiple individuals in scientific books and journals, and at conferences and symposia. On the other hand, scientific evidence also appears to be sharable, perhaps in a more direct sense, by multiple individuals making the same observations or that are involved in the same experiments. It seems to me that Kelly's view is able to account for the latter kind of publicity, but not the former, whereas there are internalist and externalist alternatives that are able to account for both kinds. Let me explain more precisely why I think that is so.

\footnotetext{
${ }^{41}$ Cf. Lyons (2016, 1058): "In order for $e$ to serve as evidence for $\mathrm{S}$ that $p$, the evidence must be taken in by $\mathrm{S}$, and done so in a way that allows $\mathrm{S}$ to in some sense appreciate its evidential significance vis-à-vis $p .$. Even if there is some sense in which beliefs are indirectly based on-and justified in virtue of being based on-extramental facts, this is only ever true in virtue of their being more proximately based on some mental state.".

42 A similar counterargument against the view that one's evidence is comprised of objects or states of affairs is offered by Neta (2008, 98-99).

43 Or the degree to which we have justification to believe them.
} 
If scientific evidence consists of physical objects and the states of affairs in which they figure, as Kelly would have it, then there is a straightforward sense in which scientists and researchers making observations (or that are involved in experiments) share the same evidence. It is after all the same objects or states of affairs that are responsible for their observations and experimental results. The scientists literally share the same scientific evidence since they make observations on the basis of the same facts (as Kelly understands the term). However, when we consider the way in which scientific evidence typically is shared in scientific books and journals, or at conferences and symposia, Kelly's view appears to be in trouble. For how can it be that physical objects or states of affairs literally are shared in journals or at conferences? There doesn't appear to be any straightforward sense in which this is possible. Indeed, it seems that the evidence that is provided in such fora is characteristically unlike the physical objects and states of affairs that are being researched.

In contrast to Kelly's position, however, internalist and externalist views according to which our evidence consists of propositions that are the contents of (some of) our attitudes can easily account for the way in which scientific evidence typically is shared in journals and at conferences. ${ }^{44}$ Such fora allow for intersubjective dissemination and appreciation of scientific evidence through testimony that usually is offered in the form of written or spoken words, or figures, graphs, models, or illustrations. Thus, testimonially transferred propositions become a source of scientific justification and knowledge of (other) inferentially supported propositions by functioning as evidence for them. ${ }^{45}$ But what about the other way in which scientific evidence typically is shared-by different individuals making the same observations? According to the internalist and externalist views under consideration, the observations in question will have propositional content that can be shared by different scientists and researchers making the (qualitatively) same (but numerically different) observations. On these views, it is such evidentially significant propositions that naturally are shared and which eventually, if all goes well, make their way into journals or books, and that are presented at conferences or symposia.

It thus seems that there are internalist and externalist alternatives that fare better than Kelly's view, both when it comes to accounting for the publicity of scientific evidence and the justifying role it plays. But what about the internalism-externalism distinction itself? Does, for example, Williamson's $\mathrm{E}=\mathrm{K}$ thesis provide a better explanation of our conception of scientific evidence than internalism? I think not. ${ }^{46}$ The reason: not only do we refer to internal states (or their propositional content) as scientific evidence, but (at times) we also rely on theories and models that, strictly speaking, are false, but which nevertheless function as evidence for various

\footnotetext{
${ }^{44}$ Cf. the quoted passage by Williamson $(2000,193)$ above.

45 Strictly speaking, figures, graphs, models, and illustrations are not necessarily propositional. But neither are strings of words. Moreover, just as strings of words often do facilitate transmission of (evidentially significant) propositions, so do figures, graphs, models, and illustrations.

${ }^{46}$ Recall from the introduction that the purpose of the paper is to evaluate whether our conception of scientific evidence fits better with externalism than internalism, and to demonstrate that the arguments purporting to show that that indeed is the case ultimately fail.
} 
hypotheses and scientifically informed beliefs. ${ }^{47} \mathrm{I}$ therefore think that a more plausible (and moderate) externalist view says that some, but not all, scientific evidence is provided by our knowledge. This kind of externalist view will not only be able to account for our use of false models and the way in which we talk about scientific evidence, but to account for its publicity and justifying role as well.

But this, however, still doesn't help us much when it comes to the internalism-externalism distinction itself. Isn't it still the case that our conception of scientific evidence supports externalism rather than internalism, you may ask. If the arguments above are sound, then that would be a premature conclusion. Indeed, the goal of this article has been to show that, contrary to what many epistemologists and philosophers of science assume, considerations of scientific evidence do not clearly support either position. More specifically, the way in which we talk about scientific evidence seems to support a moderate version of externalism, according to which both internal states and external factors (like known propositions) can provide scientific evidence. However, by reflecting on deception scenarios, it seems intuitive that only internal states can provide such evidence. I therefore suspect that the internalism-externalism debate won't be resolved until the parties agree (at least to a larger extent than what currently is the case) on more fundamental methodological issues about the epistemic significance of our philosophical intuitions and of our talk about epistemic concepts, like evidence and reason.

\section{Conclusion}

In this article, I have presented and responded to two arguments from the literature to the effect that internalism cannot account for our conception of scientific evidence. The first argument is offered (or hinted at) by Williamson, and it claims that the $\mathrm{E}=\mathrm{K}$ thesis (in contrast to internalism) provides the best explanation for the fact that scientists appear to argue from premises about true propositions (or facts) that are common knowledge among the members of the scientific community. In response, I showed that the $\mathrm{E}=\mathrm{K}$ thesis isn't supported by the way in which we talk about scientific evidence, and that it is unable to account for facts about what has been regarded as scientific evidence and as justified scientific belief in the history of science. The second argument is offered by Kelly (for example), and it claims that only externalism is suited to account for the public character of scientific evidence. In response, I argued that there are internalist views that can account for the publicity of scientific evidence, and that those views indeed do better in that regard than the (externalist) view proposed by Kelly.

The internalism-externalism debate has been raging for almost half a century, and there have been many arguments hoping to sway the opposing party to their own side. Some of the arguments that often are thought to provide a very strong case for externalism focus on our conception of scientific evidence. In this article, I have argued that those arguments fail to provide the dialectical upper hand to externalism.

47 Cf. Section 4. 
Instead, it appears that the dialectical force which the various arguments in debate have-including those that focus on scientific evidence-is hostage to disagreement about deeper methodological issues. Arguably, the most important lesson we can learn from the decades of debate is that fundamental philosophical disputes-like the internalism-externalism dispute-will not be resolved until (a larger amount of) agreement is reached between the parties about the epistemic significance of intuition, the way in which we usually talk about various concepts, and our common sense conceptions themselves. Although considerations of scientific evidence are unlikely to settle the internalism-externalism debate in the near future, it may do so given that the proper amount of attention and study is devoted to the deeper methodological issues that separate its disputants.

Acknowledgements For helpful discussions and comments, I want to thank Åsa Wikforss, Mikael Janvid, Duncan Pritchard, and Aidan McGlynn.

Funding Open access funding provided by University Of Stavanger. Work on this paper has received funding from the European Union's Horizon 2020 Research and Innovation program under Grant Agreement No. 675415.

\section{Declarations}

Conflict of interest The author declares no competing interests.

Open Access This article is licensed under a Creative Commons Attribution 4.0 International License, which permits use, sharing, adaptation, distribution and reproduction in any medium or format, as long as you give appropriate credit to the original author(s) and the source, provide a link to the Creative Commons licence, and indicate if changes were made. The images or other third party material in this article are included in the article's Creative Commons licence, unless indicated otherwise in a credit line to the material. If material is not included in the article's Creative Commons licence and your intended use is not permitted by statutory regulation or exceeds the permitted use, you will need to obtain permission directly from the copyright holder. To view a copy of this licence, visit http://creativecommons.org/licen ses/by/4.0/.

\section{References}

Arnold, A. (2011). Some evidence is false. Australasian Journal of Philosophy, 91, 165-172.

Boghossian, P. (1989). Content and self-knowledge. Philosophical Topics, 17, 5-26.

BonJour, L. (1992). Externalism/internalism. In J. Dancy \& E. Sosa (Eds.), A companion to epistemology (pp. 132-136). Blackwell.

Brogaard, B. (2018). Phenomenal dogmatism, seeming evidentialism and inferential justification. In K. McCain (Ed.), Believing in accordance with the evidence: New essays on evidentialism (pp. 53-70). Springer Verlag.

Brunero, J. (2018). Reasons, evidence, and explanations. In: D. Star (Ed.), Oxford handbook of reasons and normativity. Oxford: Oxford University Press.

Carter, A. J., et al. (2014). Varieties of externalism. Philosophical. Issues, 24(1), 63-109.

Chase, J. (2001). Is externalism about content inconsistent with internalism about justification? Australasian Journal of Philosophy, 79, 227-246.

Conee, E., \& Feldman, R. (1985). Evidentialism. Philosophical Studies, 48(1), 15-34.

Conee, E. \& Feldman, R. (2008). Evidence. In: Quentin Smith (ed.), Epistemology: New essays. (83104.) Oxford: Oxford University Press. 
Earman, J. (1993). Underdetermination, realism and reason. Midwest Studies in Philosophy, 18, 19-38.

Egeland, J. (2019). The demon that makes us go mental: Mentalism defended. Philosophical Studies, $176,3141-3158$.

Elgin, C. Z. (2017). True enough. The MIT Press.

Feigl, H. (1953). The scientific outlook: Naturalism and humanism. In: H. Feigl \& M. Brodbeck (Eds.), Readings in the philosophy of science. (8-18.) New York: Appleton-Century-Crofts.

Fitelson, B. (2010). Strengthening the case for knowledge from falsehood. Analysis, 70, 666-669.

Gettier, E. L. (1963). Is justified true belief knowledge? Analysis, 23(6), 121-123.

Glüer, K. \& Wikforss, K. (2018). Reasons for belief and normativity. In: D. Star (Ed.), Oxford handbook of reasons and normativity. Oxford: Oxford University Press.

Goldman, A. (1997). Science, publicity, and consciousness. Philosophy of Science, 64(4), 525-545.

Greco, J. (forthcoming). Justifications and excuses in epistemology. Nous, 1-37.

Grimm, S. R., Baumberger, C. \& Ammon, S. (Eds.) (2017). Explaining understanding: New perspectives from epistemology and philosophy of science.

Hempel, C. (1952). Fundamentals of concept formation in empirical science. University of Chicago Press.

Kelly, T. (2008). Evidence: Fundamental concepts and the phenomenal conception. Philosophy Compass, $3(5), 933-955$.

Kelly, T. (2016). Evidence. In: E. N. Zalta (Ed.), The Stanford Encyclopedia of Philosophy. https://plato. stanford.edu/cgi-bin/encyclopedia/archinfo.cgi?entry=evidence [Downloaded: 26.09.2018.]

Kim, J. (1988). What is "Naturalized Epistemology?" Philosophical Perspectives, 2, 381-405.

Klein, P. (2008). Useful false beliefs. In: Q. Smith (Ed.), Epistemology: New essays. (25-61.) Oxford: Oxford University Press.

Kragh, H. (1985). The fine structure of hydrogen and the gross structure of the physics community, 19161926. Historical Studies in the Physical Sciences, 15, 67-125.

Kragh, H. (2012). Niels Bohr and the quantum atom: The Bohr model of atomic structure 1913-1925. Oxford University Press.

Kuhn, T. (1996). The structure of scientific revolutions. University of Chicago Press.

Lehrer, K., \& Cohen, S. (1983). Justification, truth, and coherence. Synthese, 55(2), 191-207.

Littlejohn, C. (2012). Justification and the truth-connection. Cambridge University Press.

Lyons, J. (2016). Experiential evidence? Philosophical Studies, 173, 1053-1079.

McCain, K. (2016). Evidentialism and epistemic justification. Routledge.

McGlynn, A. (2014). Knowledge first? Palgrave Macmillan.

Neta, R. (2008). What evidence do you have? British Journal for the Philosophy of Science, 59(1), 89-119.

Pais, A. (1986). Inward bound: Of matter and forces in the physical world. Clarendon.

Pais, A. (1991). Niels Bohr's times. Oxford University Press.

Pollock \& Cruz (1999). Contemporary theories of knowledge. Rowman \& Littlefield.

Popper, K. (1959). The logic of scientific discovery. Hutchinson.

Pryor, J. (2001). Highlights of recent epistemology. British Journal for the Philosophy of Science, 52(1), 95-124.

Railton, P. (1984). Marx and the objectivity of science. In: P. Asquith \& P. Kitcher (Eds.), PSA 1984, vol. 2. East Lansing, MI: Philosophy of Science Association, 2, 813-826.

Rizzeri, A. (2011). Evidence does not equal knowledge. Philosophical Studies, 153(2), 235-242.

Smithies, D. (2012). Mentalism and epistemic transparency. Australasian Journal of Philosophy, 90(4), $723-741$.

Smithies, D. (2018). Access internalism and the extended mind. A. Carter, et al. (Eds.), Extended epistemology. (17-41.) Oxford University Press.

Turri, J. (2009). The ontology of epistemic reasons. Nous, 43(3), 490-512.

Vickers, P. (2012). Historical magic in old quantum theory? European Journal for Philosophy of Science, 2(1), 1-19.

Warfield, T. (2005). Knowledge from falsehood. Philosophical Perspectives, 19, 405-416.

Wedgwood, R. (2002). Internalism explained. Philosophy and Phenomenological Research, 65(2), 349-369.

Williamson, T. (2000). Knowledge and its limits. Oxford University Press. 
Williamson, T. (2007a). On being justified in one's head. In: Mark Timmons, John Greco, and Alfred Mele (eds.), Rationality and the good: Critical essays on the ethics and epistemology of Robert Audi. (106-122.) Oxford: Oxford University Press.

Williamson, T. (2007b). The philosophy of philosophy. Blackwell Publishing.

Wright, C. (1991). Scepticism and dreaming: Imploding the demon. Mind, 100(1), 87-116.

Publisher's note Springer Nature remains neutral with regard to jurisdictional claims in published maps and institutional affiliations. 